\title{
DISTRIBUIÇÃO DE RENDA E O DESENVOLVIMENTO ECONÔMICO: UM OLHAR SOBRE O MUNICÍPIO DE RONDON DO PARÁ
}

\author{
Elky Cris da Silva Nazaré Correio ${ }^{1}$ \\ Letícia Nascimento Maciel Correio ${ }^{2}$ \\ Tiago Soares Barcelos Correio ${ }^{3}$
}

\section{INTRODUÇÃO}

De acordo com Trovão (2020), no início do século XXI, o Brasil vivenciou um processo de crescimento com inclusão social, por estar embasado em um modelo de consumo de massa que dispôs da expansão da renda dos domicílios e do acesso ao crédito pelas famílias. Este cenário é resultado do aumento de emprego formal e de políticas sociais constituídas que intensificaram esse crescimento.

Nos dias atuais, infelizmente esse cenário se modificou, a sociedade tem vivenciado inúmeros impactos, com destaque para a situação financeira a fim de desenvolver ações que assistam os mais necessitados a partir de medidas corretivas e mais adiante preventivas, por meio de programas sociais que possam auxiliar as famílias mais afetadas nessa crise mundial. Com 0 intuito de sugerir preceitos que possam contribuir para o fortalecimento da ideia de uma política pautada no devir, este trabalho se valera das seguintes categorias analíticas: renda como direito fundamental e humano; e Renda Básica como mecanismo de diminuição de disparidade social.

Van Parijs (2000) define Renda Básica como um subsídio fornecido por uma comunidade política a fim de beneficiar a todos os indivíduos participantes, independentemente da situação financeira. Além disso, deve se apresentar como um avanço na estrutura e performance da organização do Estado e sociedade (SUPLICY, 2003).

De acordo com a Rede Brasileira de Renda Básica (RBRB) - constituída por 270 organizações e redes que defendem a campanha intitulada "Renda Básica que Queremos", foi formulado um documento fornecendo critérios a serem considerados pelos parlamentares para à

\footnotetext{
1 Instituição/Afiliação Pós-Graduanda em Gestão Pública e Tributária pelo Instituto de Ciências Sociais Aplicadas (ICSA) da Universidade Federal do Sul e Sudeste do Pará (UNIFESSPA). Graduada em Administração pelo Instituto de Ciências Sociais Aplicadas (ICSA) na Universidade Federal do Sul e Sudeste do Pará - UNIFESSPA.

${ }^{2}$ Instituição/Afiliação Pós-Graduanda em Gestão Pública e Tributária pelo Instituto de Ciências Sociais Aplicadas (ICSA) da Universidade Federal do Sul e Sudeste do Pará (UNIFESSPA). Graduada em Administração pelo Instituto de Ciências Sociais Aplicadas (ICSA) na Universidade Federal do Sul e Sudeste do Pará - UNIFESSPA.

3 Instituição/Afiliação Doutor em Geografia Humana - USP. Mestre em Sustentabilidade - UFOP Graduado em Administração e Economia. Docente da Universidade Federal do Sul e Sudeste do Pará UNIFESSPA
} 
criação de uma política pública objetivando o alcance da equidade e direitos dos cidadãos. A renda básica é um recurso com capacidade de redução de desigualdades e preservação dos direitos básicos, como também democratização e desenvolvimento econômico partindo da premissa de pagamentos realizados por institutos de finanças solidárias (Bancos Comunitários) que podem trabalhar com uma moeda social.

Levando em consideração as mudanças de cenário e os impactos que isso tem trazido para a sociedade em si, este trabalho tem como objetivo verificar como se dá essa distribuição de renda no Município de Rondon do Pará. O foco consiste principalmente nas famílias que se utilizam de programas sociais para terem ou complementarem sua renda per capita, de modo que se busque entender até que ponto estes programas se fazem necessário para essas famílias.

Além desta introdução este artigo traz na segunda seção um conciso procedimento metodológico e na terceira seção um breve apanhado histórico bibliográfico acerca da desigualdade e o papel das Políticas Públicas. Na sua quarta seção apresentamos o processo de ocupação do território de Rondon do Pará, para que se possa compreender a sua evolução temporal e espacial e suas principais características. Na quinta seção se tem uma visão da situação do Brasil e do território em questão quando se fala em Distribuição de Renda e Desenvolvimento Humano. Na última seção serão feitas as considerações acerca dos resultados obtidos nesta pesquisa, assim como sugestões baseadas nos achados para se obter possíveis melhorias no processo como um todo.

\section{METODOLOGIA}

O estudo se caracteriza como qualitativo, a fim de perceber, expor e elucidar os fenômenos sociais, ponderando experiências dos sujeitos ou grupos, analisando interações que eventualmente podem se desenvolver e pesquisando documentos, como textos e imagens ou circunscrições semelhantes de experiências e conexões (FLICK, 2009). A metodologia desta pesquisa é sustentada por um referencial exploratório que orienta as questões e proposições do estudo, com o intuito de testar a teoria reunindo uma gama de informações obtidas por meio de diversas técnicas de levantamento de dados e evidências (MARTINS, 2008). Por fim, apresenta como método a exploração bibliográfica para a verificação de informações básicas a respeito de aspectos direta e indiretamente ligados ao tema baseado em livros, trabalhos científicos, assim como sites oficiais das instituições de pesquisas (GIL, 2002).

O propulsor deste artigo incide em verificar como acontece a distribuição de renda nas famílias que se utilizam de programas sociais para terem ou complementarem sua renda per capita no Município de Rondon do Pará, de modo que se perceba até que ponto estes programas se 
fazem necessário para essas famílias. Para isso, os dados foram obtidos a partir do levantamento de conceitos e referências teóricas de estudos já publicados acerca do tema, por meios eletrônicos, artigos científicos, e sites estatísticos de dados secundários do governo, principalmente o site da prefeitura municipal de Rondon do Pará.

\section{CONTEXTO HISTÓRICO SOBRE A DESIGUALDADE E A LEI DOS POBRES}

No decorrer do século XIV, a Europa Ocidental era assolada pela peste, acarretando drásticas mudanças sociais, e as Monarquias medievais passaram a intervir de fato sobre a pobreza que aumentava consideravelmente devido a essas calamidades. A Inglaterra se destaca por possuir um governo empenhado a amenizar tais problemas, visto que a Dinastia Tudor (14851603) estava focada em estabelecer diretrizes mitigadoras em relação a pobreza, obrigando toda pessoa sadia a trabalhar e coibindo a circulação de desocupados (GEREMEK, 1986).

Conforme Bastos (2018), com o tempo o cenário se modifica, o problema se adapta e no século XVI emerge um novo padrão de pobreza diferente dos séculos anteriores, sendo eles classificados como: merecedores (perfil de alguém que não possuía as habilidades e capacidade necessárias para o trabalho, e com isso era merecedor de caridade), e vagabundos (indivíduo que preferia a indolência). $O$ autor retrata ainda o desafio do regime Tudor, sobre suas atitudes em relação aos trabalhadores desempregados e os subempregados (indivíduos habilitados e ansiosos para ganhar seu sustento, mas sem oportunidades para fazê-lo). Essas mudanças tornam-se resultados das relações econômicas características da transição feudalismo-capitalismo agrário.

A partir do século XVIII observou-se um aumento considerável nas despesas retratada por pobres e as reclamações em relação ao sistema passa a serem mais constantes. Isso resulta de algumas mudanças pela perspectiva socioeconômica da época, como: o cercamento das terras comuns e a criação de pastagens e a expansão da indústria lanígera que impulsionou a Inglaterra ao setor têxtil, motivando à revolução industrial (ANTONIO SAVARIS, 2019; BASTOS, 2018).

Por mais lamentável que seja a desigualdade, entende-se que ela é oriunda da relação entre proprietários e os sem posses, sendo esses coagidos a vender sua força de trabalho mediante a ameaça da fome. Esse foi o principal motivador ao trabalho, pois quanto mais pobre, mais está habituado às mais desprezíveis atividades, aos trabalhos mais árduos e aos mais diversos perigosos laborais na esperança de obter uma boa recompensa (TOWNSEND, 1817; MALTHUS, 1998).

Normas inglesas foram compiladas no reinado de Elizabeth I, para benefício legal dos pobres dando origem a primeira lei oficial dos pobres, intitulada The 1601 Act for the Relief of the 
Poor (A Lei de 1601 para o alívio dos pobres). O financiamento ocorria essencialmente por impostos e taxas locais que advinham sobre todos os donos de casas e locatários, ricos ou não, considerando o aluguel das terras ou casas que ocupavam. O subsídio da paróquia estava sujeito a condição do pobre, como asilos para os velhos e enfermos, as esmolas, o ensino de profissão para órfãos e crianças carentes, acondicionamento de ofício para homens capazes ou cárcere para os que podiam, mas se recusavam a trabalhar.

Em 1601, com uma necessidade viável à mudança para nova ordem econômica, a Lei dos Pobres passaria a direcionar oficialmente toda a gestão pública em relação aos pobres, antecipando a cobrança de um imposto recolhido e administrado pelo Estado, a ser pago pelos ricos e destinada à ajuda aos pobres (VISCARDI, 2011). Seu propósito era garantir um mínimo que fosse de benefícios aos camponeses que não teriam acesso a terras e estariam a mercê da instabilidade do mercado de trabalho (PATRIQUIN, 2007; WOOD, 2001). Assim sendo, em detrimento da falta do bem que possibilitava o sustento aos trabalhadores do campo se tornaria 0 choque à segurança social (ANTONIO SAVARIS, 2019).

Em 1834 a lei dos Pobres foi reformulada e passou atuar como um motriz do Estado de Bem-Estar Social, implementado na Inglaterra em meados do século XX. Era disponibilizando um auxílio básico, além de salário, como comida, moradia, vestuário, carvão e auxílio funeral (KIDD, 1999). A "Nova Lei dos Pobres", era descentralizada e gerenciada localmente, cada governante dispunha de autonomia para assessorar sua comunidade da melhor maneira possível. Obstáculos apareceram na maneira de administrar a Nova Lei dos Pobres que inviabilizam seu andamento em comparação ao planejado, mas politicamente, é um resultado positivo para a economia de mercado, em que o valor da força de trabalho precisaria ser regulado organicamente pela relação entre oferta e demanda (VISCARDI, 2011).

\section{OCUPAÇÃO DO TERRITÓRIO E UM BREVE HISTÓRICO DE RONDON DO PARÁ}

A evolução da ocupação do território da Amazônia, principalmente quando se fala da Amazônia Oriental, o qual compreende o Estado do Pará e o território de Rondon do Pará, tem como características no século XX e XXI sinais de relativo isolamento em relação às demais regiões brasileiras. O Estado do Pará é dívida em seis mesorregiões, conforme o Figura 1, em que o município de Rondon do Pará está inserido da Mesorregião do Sudeste do Pará. O desenvolvimento econômico e social do sudeste paraense pode ser compreendido por três fases. 
Figura 1- Mesorregiões paraenses

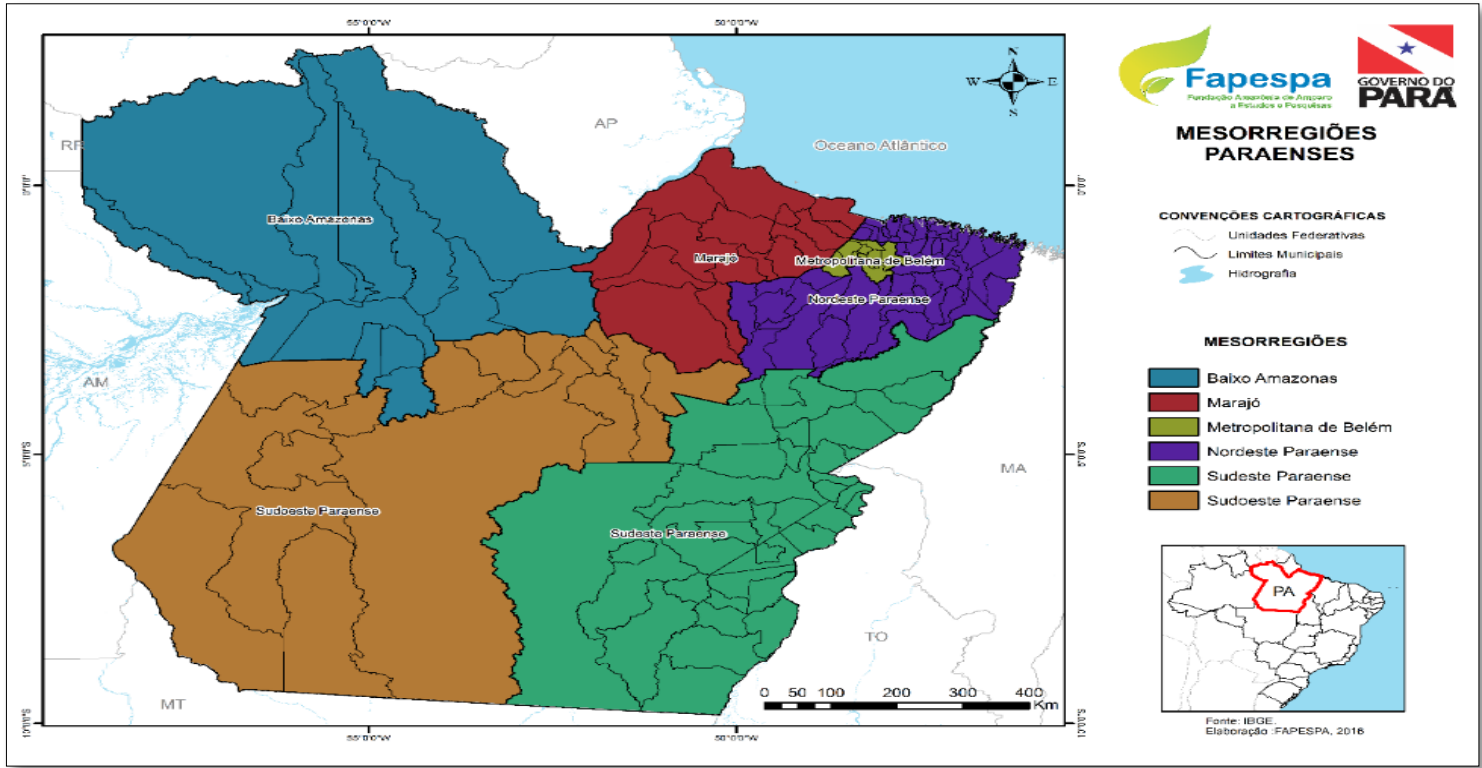

Fonte: Fapespa (2016)

A primeira fase tem origem a partir do século XVII, sendo iniciada a ocupação da região amazônica brasileira. O rio Tocantins constitui-se a principal via de acesso desse período, dado um processo de desbravamento e controle do território dos colonizadores portugueses. Nesse processo, a estrutura utilizada foi a fundação de Belém, em 12 de janeiro de 1616, com o objetivo de fixação dos brancos nos territórios habitados por povos indígenas. Essa primeira fase vai até metade do século XIX em que a principal força econômica são produtos de exploração florestal para exportação, como: madeira, plantas medicinais, cravo, canela, entre outros (GOLDERS ASSOCIATE, 2004).

A segunda fase está relacionada ao ciclo da borracha e as descobertas das jazidas minerais. A partir da segunda metade do século XIX é ampliado a migração de pessoas ao território em questão, principalmente durante 0 auge da borracha (1890-1910), representando uma fatia considerável das exportações brasileira, com forte peso no balanço de pagamentos. Nesse período é fundado o município de Marabá (1889) e Conceição do Araguaia (1897), tornando, a posteriori, polos urbanos da região. Em 1913, a produção de borracha colapsa no Brasil, que entra em crise, não contribuindo para o desenvolvimento regional (acumulação de capital regional). Isso implicou na redução de produção de alimentos e criou enclaves econômicos, provocando um vazio na economia regional, que só voltou a melhorar apenas na Segunda Guerra Mundial. De modo a buscar alternativas, no ano de 1927, Marabá assume uma posição de destaque nas exportações de castanha-do-pará. No ano de 1937 há um aumento populacional devido ao garimpo de 
diamantes, visto que na década de 1960 se observa o potencial mineral da província de Carajás (GOLDERS ASSOCIATE, 2004).

A terceira fase da ocupação do território é incentivada por políticas governamentais de desenvolvimento da região, cujo a pauta central é a consolidação da atividade minerária. Com 0 Plano de Metas do governo Juscelino Kubitschek (1956-1961) foi construído as rodovias BelémBrasília (BR-010) e Cuiabá-Porto Velho (BR-364), criando um ponto de inflexão no perfil econômico e demográfico da região. Altvater (1989), reforça que na década de 1950 a região tornou-se alvo de uma intervenção estatal, centralizada, qualificada e planejada, cujo o objetivo era integrar a região com o circuito econômico nacional. Para tal, o objetivo consistia em uma nova dinâmica do capital industrial, por meio de uma política de substituição de produtos manufaturados, carecendo de matéria-prima.

Na década de 1960 há interesse por parte de investidores internacionais com relação as riquezas minerais próximas da região de Marabá, dado as jazidas de minério descobertas na região do Carajás. Para ocupação produtiva no território, o governo lança o I Plano Nacional de Desenvolvimento (1972/1974) e o II Plano Nacional de Desenvolvimento (1975/1979). Por iniciativa do governo federal surge no final da década de 1980 o Projeto Grande Carajás (PGC), com o objetivo de uma coordenação política de desenvolvimento da Amazônia Oriental (GOLDERS ASSOCIATE, 2004).

Desse período, até o momento, constitui-se a terceira fase de ocupação do território do sudeste paraense. Nesse contexto, há uma ampliação da migração de contingentes expressivos da sociedade brasileira, em especial, pessoas oriundas do nordeste brasileiro, buscando terras e melhores condições de vida. Dessa forma, estabelece no território posseiros, fazendeiros, madeireiros, indígenas, quilombolas, camponeses, latifundiários, industriais, cujo foco é a pecuária e na extração de recursos florestais e minerais, ocasionando os mais diversos conflitos pela terra.

A constituição da ocupação do território dessa região foi calcada a partir de uma lógica puramente econômica, incentivadas por políticas governamentais, mas se diferenciando das outras fases históricas de ocupação do Estado. Para consolidar os novos territórios, baseado em uma geopolítica de ocupar para integrar, o governo apresenta uma matriz com diretrizes, criando empreendimentos e instrumentos institucionais que permitissem essa consolidação, calcado em incentivos tributários e desconsiderando as populações tradicionais. Como reflexo dessas políticas, intensificadas nas últimas cinco décadas, há uma expansão demográfica no território.

Conforme as informações do IBGE o município de Rondon do Pará teve origem em fins de 1962, com os trabalhos de demarcações das primeiras fazendas. Porém, o povoamento do atual efetivo do atual território somente ocorreu, em 1968, quando o Departamento de Estradas 
de Rodagens implantou ali o seu primeiro acampamento, dando início à abertura da rodovia PA70. É importante destacar que o Governo Federal prometia terras aos migrantes, informando por rádio: "venha para a Amazônia, a terra sem homens para os homens sem-terra; vamos integrar a Amazônia para não entregar" (CNEC; WORLEY PARSON, 2012, p. 7). Conforme as máquinas do Departamento de Estradas e Rodagens (DER) avançava no território, as pessoas alegavam direito a posse das terras, construindo estruturas para garantir a propriedade.

Nessa época, a localidade passou a ser conhecida por Candangolândia de Arinos Brazil. Após a criação do Projeto Rondon, pelo Governo Federal, Candangolândia prosperou e, em 1969, já contando com 1 posto de gasolina, uma farmácia e um açougue, passou a chamar-se Vila Rondon. Essa denominação, entretanto, perdurou até 1982 (lei estadual n 5027, de 13-05-1982), quando adquiriu categoria de município com o nome de Rondon do Pará4.

O município de Rondon do Pará surge devido a política de abertura de rodovias, como política pública por parte do governo. Almejando o desenvolvimento, a partir de 1950 há uma mudança de visão e postura do Governo Federal com o território Amazônico, baseado em um programa de planejamento central, abrindo por exemplo a rodovia BR-222 (antiga PA-70), em 1968. Os povos indígenas foram os primeiros habitantes do território, o que ocasionou os mais diversos conflitos, sendo descolocados dessa região, mudando para a proximidade de Marabá, como a reserva indígena de Mãe de Maria.

É importante destacar que nesse período histórico mais de 200 famílias moravam na Vila Rondon, e cada dia chegavam mais pessoas, devido as terras baratas e incentivos do governo. Pode-se dizer que o município de Rondon do Pará surgiu em 17 de julho de 1967 por meio do acampamento dos funcionários da DER, e posteriormente, com a entrada de fazendeiros, industriais e comerciantes, transformando o território por uma perspectiva econômica e política, com uma ocupação espontânea e desordenada. Assim sendo, surge os mais diversos conflitos agrários, com destaque para os conflitos com os índios Gaviões, a guerrilha dos americanos entre outros. Com a chegada de posseiros, fazendeiros e grileiros ao território, resulta em inúmeras mortes por pistolagem nos conflitos fundiários, nas invasões ou ocupações de terras. Um exemplo que resultou em várias mortes foi o conflito de 25 de julho de 1969, entre povos indígenas e fazendeiros, que só foi contido com a chegada de um destacamento da Polícia Militar de Belém (CNEC; WORLEY PARSON, 2012).

No período de 2000 a 2010 a população de Rondon do Pará cresceu a uma taxa média anual de aproximadamente $1,65 \%$, sendo que a média brasileira é de $1,17 \%$ para o mesmo

\footnotetext{
${ }^{4}$ Informações extraídas do sítio eletrônico: https://cidades.ibge.gov.br/brasil/pa/rondon-dopara/historico Acesso, 04 de novembro 2020.
} 
período. A taxa de urbanização passou de 75,40\% para 73,88\% e em 2010 viviam no município 46.964 pessoas, visto que a estimativa do IBGE para 2019 são de 52.357 habitantes. A área total do município é de $8.246,394 \mathrm{~km}^{2}$ com uma densidade populacional de $6,3 \mathrm{hab} / \mathrm{km}^{2}$. A evolução populacional pode ser melhor compreendida na Tabela 1. A estrutura etária nesse mesmo período teve sua razão de dependência, ou seja, o percentual da população de menos de 15 anos e mais de 65 anos, de $63,25 \%$ para $51,27 \%$, conforme pode ser observado na Figura 2 (ATLASDOBRASIL, 2020).

Tabela 1: População total, por gênero, rural/urbano de Rondon do Pará

\begin{tabular}{|c|c|c|c|c|c|c|}
\hline População & $\begin{array}{r}\text { População } \\
\text { (1991) }\end{array}$ & $\begin{array}{r}\% \text { do Total } \\
\text { (1991) }\end{array}$ & $\begin{array}{r}\text { População } \\
(2000) \\
\end{array}$ & $\begin{array}{r}\% \text { do Total } \\
(2000)\end{array}$ & $\begin{array}{r}\text { Populaçäo } \\
(2010) \\
\end{array}$ & $\begin{array}{r}\% \text { do Total } \\
\text { (2010) }\end{array}$ \\
\hline População total & 31.674 & 100,00 & 39.870 & 100,00 & 46.964 & 100,00 \\
\hline $\begin{array}{l}\text { Populaçäo residente } \\
\text { masculina }\end{array}$ & 16.399 & 51,77 & 20.317 & 50,96 & 24.274 & 51,69 \\
\hline $\begin{array}{l}\text { População residente } \\
\text { feminina }\end{array}$ & 15.276 & 48,23 & 19.553 & 49,04 & 22.690 & 48,31 \\
\hline População urbana & 21.472 & 67,79 & 30.061 & 75,40 & 34.696 & 73,88 \\
\hline População rural & 10.202 & 32,21 & 9.809 & 24,60 & 12.268 & 26,12 \\
\hline
\end{tabular}

Fonte: PNUD, Ipea e FJP.

Figura 2: Pirâmide Etária - Rondon do Pará: distribuição por sexo, segundo os grupos de idade

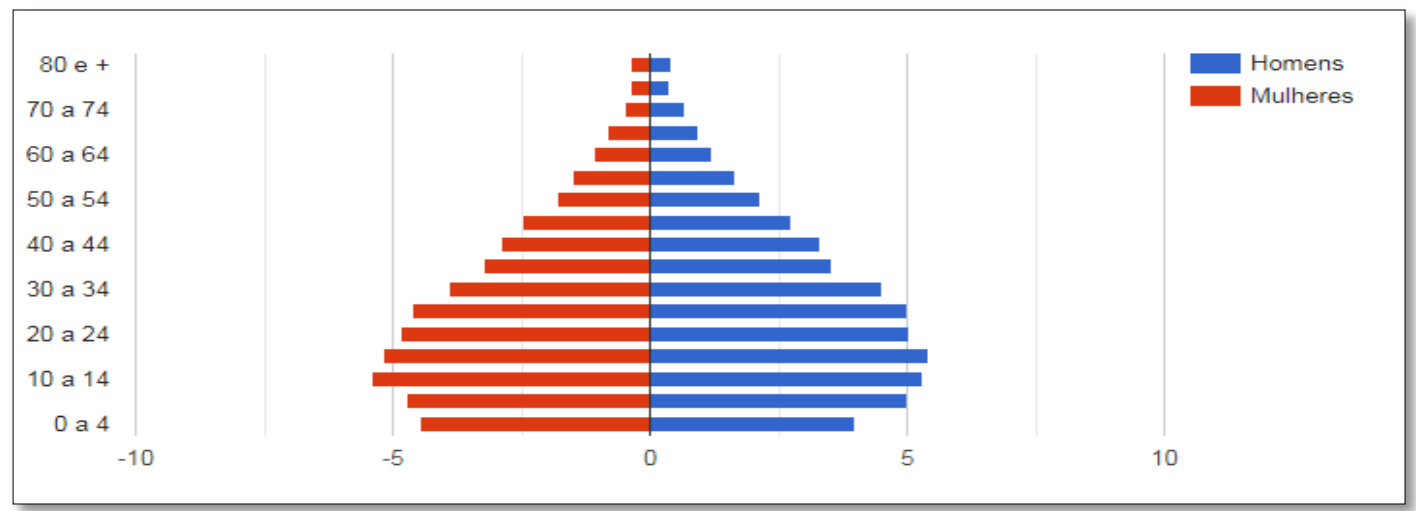

Fonte: PNUD, Ipea e FJP.

Percebe-se, portanto, que o município de Rondon do Pará nasce de um processo com os mais diversos conflitos, resultando em arranjos territoriais desiguais. Diante dessa disputa, a população local constitui-se majoritariamente em famílias de baixa renda, sendo necessário um olhar atendo a distribuição da abundância da riqueza e recursos naturais do seu entorno. No próximo tópico serão debatidos essa relação, apresentando alguns elementos importantes para a compreensão da totalidade geográfica ao local. 


\section{DISTRIBUIÇÃO DE RENDA E PÚBLICO ALVO DE RONDON DO PARÁ}

De acordo com as informações contidas no Relatório de Desenvolvimento Humano (2019), apresentado em 09 de dezembro de 2019 pela PNUD, o Brasil se encontra em $79^{\circ}$ lugar no Ranking de um total de 189 países detendo um IDH de 0,761; considerado um bom resultado, 0 classificando como um país de desenvolvimento humano elevado. Em contrapartida no mesmo relatório obteve um total de 0,533 ( 0 a 1) no Coeficiente de Gini, demonstrando uma desigualdade considerável. Nos próximos tópicos será explicado esses dois indicadores e sua importância, além de uma análise relacionada ao município de Rondon do Pará.

\section{1 Índice de Desenvolvimento Humano (IDH) e a situação do município}

A definição de desenvolvimento humano, assim como sua medida, o Índice de Desenvolvimento Humano - IDH - é empregado para se avaliar a qualidade de vida oferecida à população de cada país. Considera-se como métrica a riqueza, a saúde e a educação, essa realizada anualmente pela Organização das Nações Unidas (ONU). Utilizam-se de uma metodologia complexa pontuando os países analisados de zero a um e passam a ser classificados em desenvolvidos, em desenvolvimento ou subdesenvolvidos. Significa que quanto mais próximo de zero, pior são as condições de educação, saúde e renda da população; e quanto mais próximo de um, melhores são essas condições (GUIMARÃES; DE MARTINO JANNUZZI, 2005).

O índice de Educação é medido pela taxa de alfabetização ou escolarização; a saúde é baseada na expectativa de vida, ou seja, quanto tempo se espera que uma pessoa viverá no país observado. Desse modo, são avaliadas as condições de saúde e educação do território, bem como a renda pondera o Produto Interno Bruto (PIB) conhecida como per capita. Dessa forma, utiliza-se o dólar americano como moeda padrão, somando toda riqueza produzida por um país anualmente, dividido pelo número de habitantes. Ademais, o IDH é apenas mais uma maneira padronizada de se avaliar e medir o bem-estar de uma população, não retratando necessariamente a realidade deste país (PINTO, 2013).

Dessa forma, a nível municipal, foi criado o IDH-M, calcado em três pilares (vida longa e saudável, acesso ao conhecimento e padrão de vida), variando de 0 a 1. O IDH-M do município de Rondon do Pará, conforme o senso do IBGE de 2010, está no valor de 0,6025, índice no limite da faixa média $(0,600$ a 0,699$)$. A metodologia do IDH-M possui 5 faixas (muito alto, alto, média,

\footnotetext{
${ }^{5}$ O Índice de Desenvolvimento Humano (IDHM) - Rondon do Pará é 0,602, em 2010, o que situa esse município na faixa de Desenvolvimento Humano Médio (IDHM entre 0,600 e 0,699). A dimensão que mais contribui para o IDHM do município é Longevidade, com índice de 0,788, seguida de Renda, com índice de 0,606, e de Educação, com índice de 0,457 (ATLASBRASIL, 2020).
} 
baixo e muito baixo), e dado o município de Rondon do Pará se encontrar nessa faixa (médio). A Figura 3 apresenta os pilares e a evolução histórica do IDH-M do município de Rondon do Pará.

Figura 3: Índice de Desenvolvimento Humano em Rondon do Pará

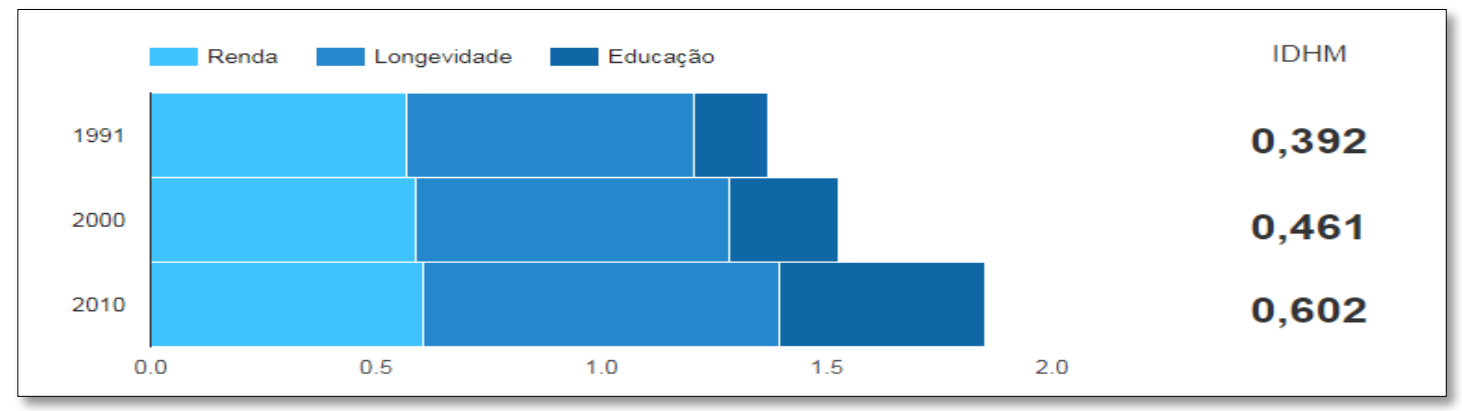

Fonte: PNUD, Ipea e FJP.

Outra métrica importante que integra o IDH-M é a escolaridade da população acima de 18 anos ou mais, com ensino fundamental completo. Esse indicador carrega uma inércia, visto o peso das gerações mais antigas, que possuem menor escolaridade. Entre 2000 e 2010 esse percentual passou de 19,86 para 33,69\%, no município de Rondon do Pará. No ano de 2010, considerando a população acima de 25 anos, $26,22 \%$ eram analfabetos, $28,18 \%$ tinham o ensino fundamental completo, $14,76 \%$ possuíam o ensino médio completo e $3,71 \%$, o superior completo (Figura 4). No Brasil, esses percentuais são, respectivamente, $11,82 \%, 50,75 \%, 35,83 \%$ e $11,27 \%$. A população economicamente ativa do município pode ser visualizada na Figura 5 (ATLASBRASIL, 2020).

Figura 4: Escolaridade da população de Rondon do Pará

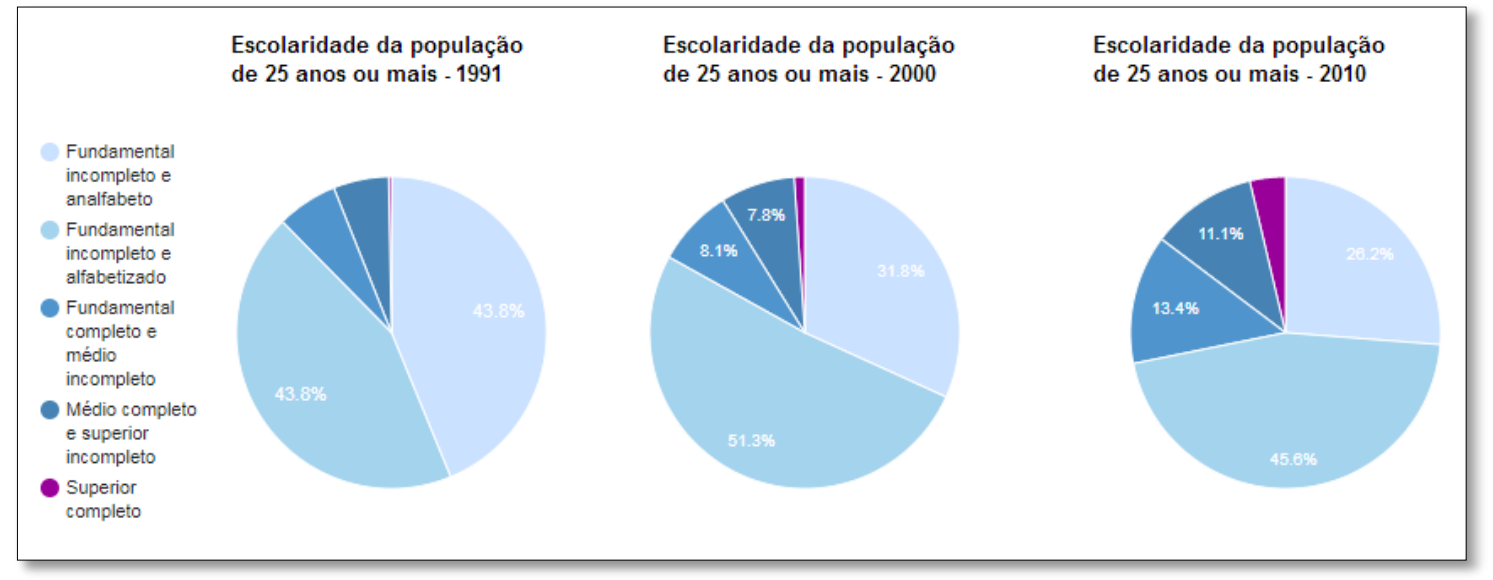

Fonte: PNUD, Ipea e FJP. 
Figura 5: População economicamente ativa de Rondon do Pará

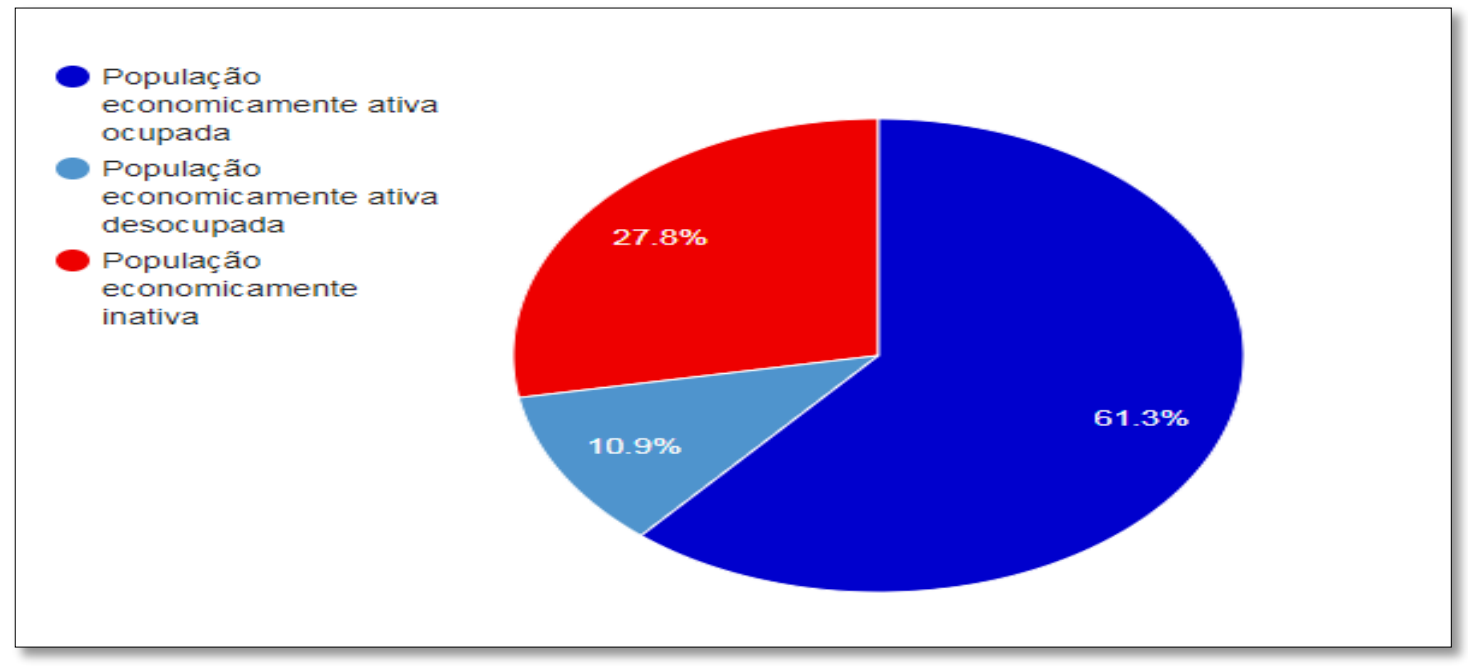

Fonte: PNUD, Ipea e FJP.

\subsection{Coeficiente de Gini e a situação do município}

O coeficiente de Gini ou índice de Gini proporciona a compreensão sobre a situação econômica e social de uma país, por meio da desigualdade, tornando evidente a diferença da distribuição de renda entre ricos e pobres, conseguindo medir essa renda sem sofrer limitações de outros dados como por exemplo a renda per capita. Basicamente, considera-se valores entre 0 e 1, dessa maneira, entende-se que se o valor se aproxima de zero, menor é a desigualdade, ou se 0 valor se aproximar de um, maior será a desigualdade existente no país analisado. Por exemplo, infere-se que se um país possuir o indicador igual a zero significa que todos os indivíduos possuem a mesma renda, e se possuir um indicador igual a um, significaria que toda riqueza praticamente estaria concentrada no poder de apenas um indivíduo, portanto, percebe-se que não existem países com os índices extremos de Gini, mas é necessário um desempenho constante para que ele se aproxime o máximo possível de zero (IPECE, 1986).

Em Rondon do Pará o Índice de Gini, para o ano de 2010, foi mensurado em 0,5647, demonstrando que o município possui uma concentração de renda considerável. A renda per capita de Rondon do Pará cresceu $25,57 \%$ nas últimas duas décadas, passando de $\mathrm{R} \$ 276,13$, em 1991, para $\mathrm{R} \$ 346,74$, em 2010 , com uma taxa média anual de crescimento de $1,21 \%$. 0 percentual dos extremamente pobres passou de 13,26\%, em 1991, para 14,11\%, em 2010, e 0 percentual de pobres passou de 43,72\%, em 1991, para 30\% em 2010 (Tabela 2). Outros indicadores importantes, como os indicadores de habitação e vulnerabilidade social, são apresentados na Tabela 3 e Tabela 4, proporcionando assim, as condições de vida da população local (ATLASBRASIL, 2020). 
Tabela 2: Renda, pobreza e desigualdade do município de Rondon do Pará

\begin{tabular}{lrrrr} 
& 1991 & 2000 & 2010 \\
\hline Renda per capita & 276,13 & 314,13 & 346,74 \\
\hline$\%$ de extremamente pobres & 13,26 & 15,97 & 14,11 \\
\hline$\%$ de pobres & 43,72 & 40,39 & 30,00 \\
\hline Indice de Gini & 0,54 & 0,58 & 0,54
\end{tabular}

Fonte: PNUD, Ipea e FJP.

Tabela 3: Indicadores de Habitação de Rondon do Pará

\begin{tabular}{lcccc} 
& 1991 & 2000 & 2010 \\
\hline \% da população em domicillios com água encanada & 32,29 & 35,95 & 84,44 \\
\hline \% da população em domicílios com energia elétrica & 61,79 & 83,12 & 89,83 \\
\hline \% da população em domicílios com coleta de lixo & 48,34 & 82,21 & 93,72
\end{tabular}

Fonte: PNUD, Ipea e FJP.

Tabela 4: Vulnerabilidade social de Rondon do Pará

\begin{tabular}{|c|c|c|c|}
\hline Crianças e Jovens & 1991 & 2000 & 2010 \\
\hline Mortalidade infantil & 52,15 & 38,32 & 20,50 \\
\hline$\%$ de crianças de 0 a 5 anos fora da escola & - & 84,38 & 71,00 \\
\hline$\%$ de crianças de 6 a 14 fora da escola & 35,93 & 17,57 & 8,17 \\
\hline $\begin{array}{l}\text { \% de pessoas de } 15 \text { a } 24 \text { anos que não estudam, não trabalham e são vulneráveis, na população } \\
\text { dessa faixa }\end{array}$ & - & 21,75 & 25,81 \\
\hline$\%$ de mulheres de 10 a 17 anos que tiveram filhos & 2,11 & 4,18 & 7,31 \\
\hline Taxa de atividade - 10 a 14 anos & - & 11,74 & 9,00 \\
\hline \multicolumn{4}{|l|}{ Família } \\
\hline $\begin{array}{l}\% \text { de mães chefes de família sem fundamental e com filho menor, no total de mães chefes de } \\
\text { família }\end{array}$ & 12,19 & 17,84 & 25,93 \\
\hline$\%$ de vulneráveis e dependentes de idosos & 2,09 & 3,09 & 3,36 \\
\hline$\%$ de crianças extremamente pobres & 17,33 & 21,71 & 18,27 \\
\hline \multicolumn{4}{|l|}{ Trabalho e Renda } \\
\hline$\%$ de vulneráveis à pobreza & 71,00 & 69,53 & 60,53 \\
\hline$\%$ de pessoas de 18 anos ou mais sem fundamental completo e em ocupação informal & - & 67,99 & 58,06 \\
\hline \multicolumn{4}{|l|}{ Condição de Moradia } \\
\hline \% da população em domicílios com banheiro e água encanada & 31,03 & 30,89 & 65,52 \\
\hline
\end{tabular}

Fonte: PNUD, Ipea e FJP.

Percebe-se, portanto, uma precária condição de vida no município, algo que se reflete ao Estado do Pará como um todo, apresentando um baixo nível de renda, baixo acesso à água 
encanada, baixo nível de saneamento básico, elevada desigualdade social, alto índice de criminalidade e vulnerabilidade social, entre outras métricas.

\subsection{Níveis de Rendimento e Desigualdade Regional e Municipal}

Além do Coeficiente de Gini que mostra um alto nível de desigualdade quando se fala em mensuração do grau de concentração de renda, de acordo com o Relatório da PNUD 2019 a desigualdade de rendimento no Brasil era de 36,7\%. Sendo que no período entre 2010 a 20170 rendimento e/ou consumo se deu pelos subgrupos populacionais, conforme a Tabela 5.

Tabela 5: Percentual de rendimento e/ou consumo de acordo com subgrupos populacionais

$40 \%$ mais pobres

$10,6 \%$
$10 \%$ mais ricos

\section{$1 \%$ mais ricos}

Quanto mais próximo de 10 coeficiente de Gini for, maior é a desigualdade na distribuição de renda da população, ou seja, para esse índice cair é preciso que a população mais pobre comece a se apropriar de uma quantia maior dessa renda total da sociedade (BARROS; FOGUEL; ULYSSEA, 2006).

Segundo informações da Pesquisa Nacional por Amostra de Domicílios Contínua - PNAD no ano de 2019, o rendimento domiciliar per capita por região pode ser melhor compreendido na Figura 6.

Figura 6: Rendimento domiciliar per capita, por região, em 2019

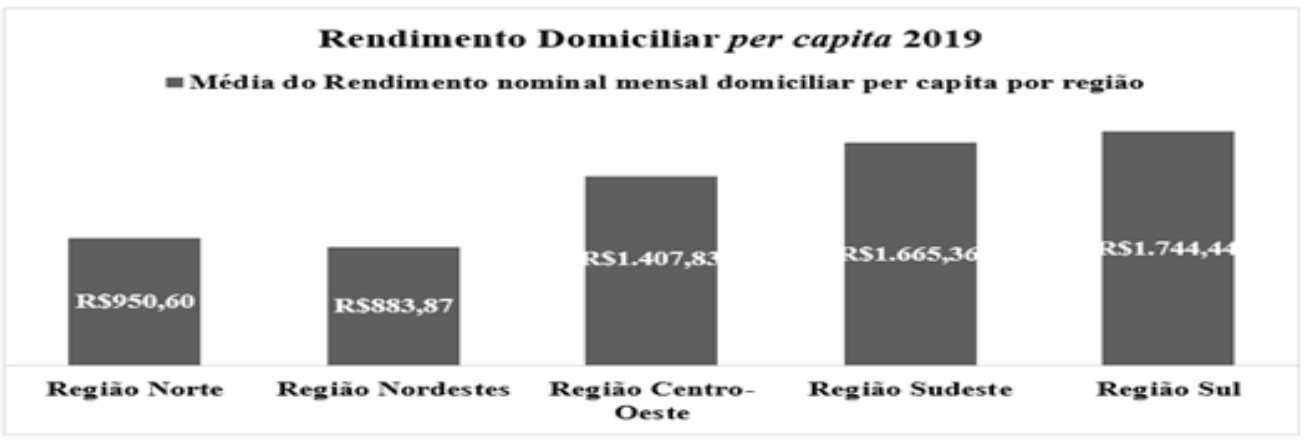

Fonte: PNAD Contínua (2019). Elaborado pelos autores (2020). 
Observa-se que a Região Norte e Nordeste são as regiões brasileiras que possuem as menores médias de rendimento. Os números mostram que a Região Norte e a Região Nordeste são $83,50 \%$ e 97,36\% menor que o rendimento per capita da Região Sul; um valor muito relevante que chama atenção para a disparidade entre as regiões. Voltando os olhares apenas para a Região Norte e os seus 07 (sete) estados pode-se observar a origem da média da região (Figura 7).

Figura 7: Rendimento domiciliar per capita na Região Norte em 2019

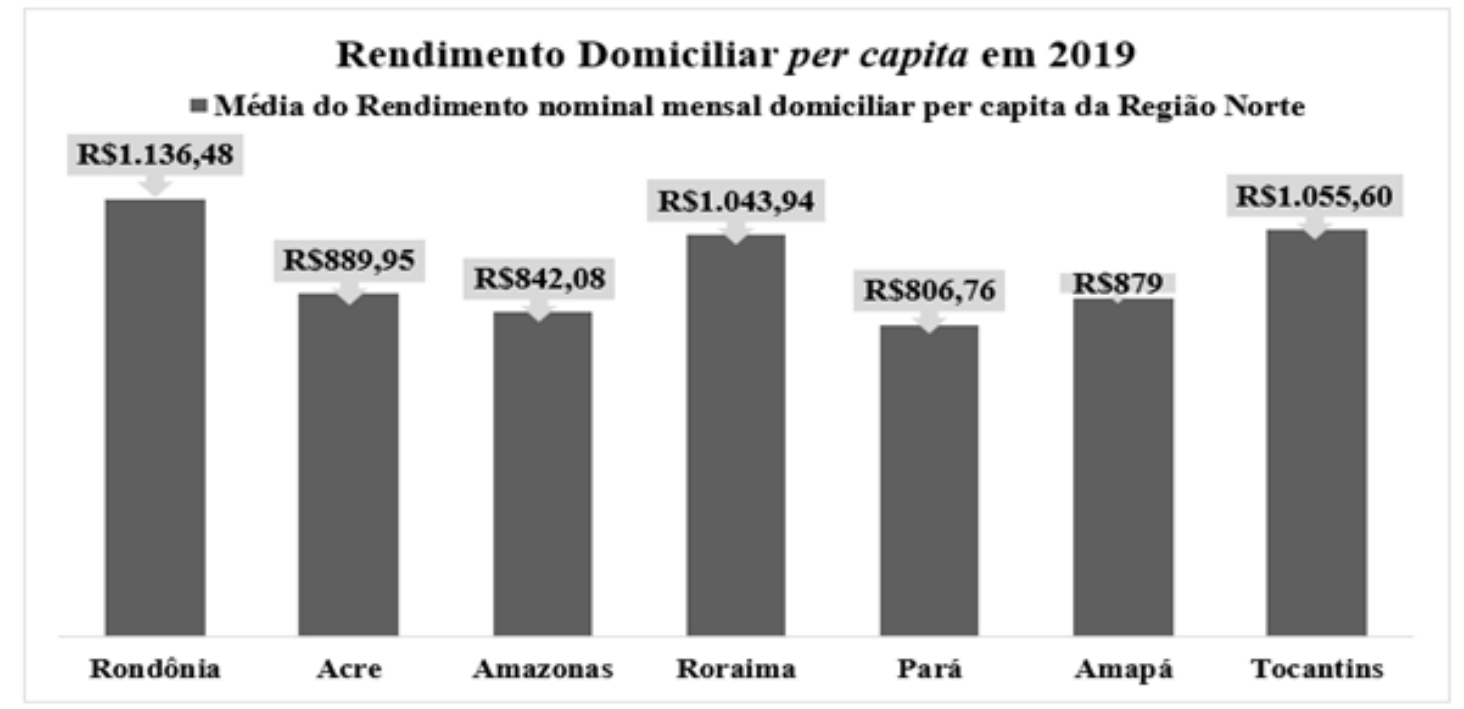

Fonte: PNAD Contínua (2019). Elaborado pelos autores (2020).

Percebe-se que o Estado do Pará possuí o menor rendimento com $\mathrm{R} \$ 806,76$ comparado aos demais, sendo que $57,14 \%$ dos estados não chegaram nem a soma de um salário mínimo; e se comparado aos estados das demais regiões do Brasil fica atrás apenas do Maranhão que possuí uma média de R $\$ 635,59$. Segundo dados do IBGE a população no ano de 2010 era de 7.581 .051 (milhões) de habitantes, e em uma estimativa para o ano de 2020 esse número seria de 8.690 .745 (milhões) de habitantes.

O Estado se dividi em 144 municípios e abrange um total de 14,65\% do território brasileiro. Sendo que o município abordado neste trabalho é o de Rondon do Pará, que de acordo com o último censo divulgado pelo IBGE (2010) possuí 46.964 habitantes, e que em uma estimativa feita no período de 01 de julho de 2020 este número poderia chegar a uma quantidade 52.803 habitantes no ano de 2020 (IBGE). 
Levando em consideração os últimos 05 (cinco) anos de 2016 até 2020 o Município de Rondon do Pará já recebeu um total de $\mathrm{R} \$ 48.745 .620,73$ (Milhões) em Benefícios aos Cidadãos como pode se observar na Figura 8.

Figura 8: Valor repassado aos beneficiários de Rondon do Pará

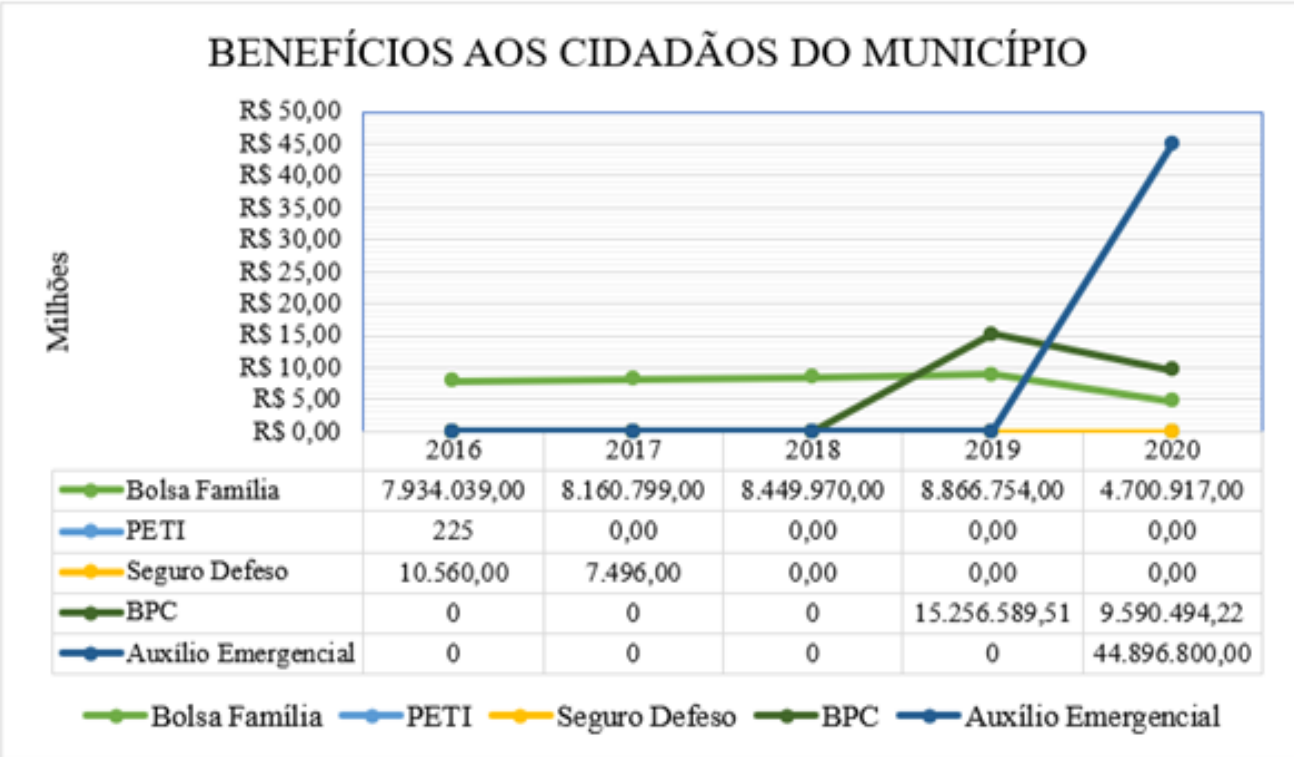

Fonte: Portal da Transparência de Rondon do Pará (2019). Elaborado pelos autores (2020).

Observa-se que ainda se tem uma grande parcela de pessoas que se utilizam dos benefícios do governo, sendo então essas políticas públicas de grande importância para 0 desenvolvimento econômico e social do município. Chama atenção para os Benefícios que mais atendem a população sendo eles: Bolsa Família - PBF, Benefício de Prestação Continuada - BPC e a última medida do governo no ano atual de 2020 o Auxilio Emergencial, decorrente da Pandemia da Covid-19 que vem assolando todo o mundo.

No ano de 2020 um detalhe que chama atenção referente ao auxílio emergencial da Medida Provisória no 937'15, de 2 de abril de 2020, como pode-se observar na Tabela 6 .

Tabela 6: Benefícios, valores e quantidade dos beneficiários de Rondon do Pará

PROGRAMA TOTAL RECEBIDO PELA QUANTIDADE DE LOCALIDADE BENEFICIADOS

\begin{tabular}{ccc}
\hline Auxilio Emergencial & R\$ $44.896 .800,00$ & 15.810 \\
\hline Bolsa Familia & R\$ $4.700 .917,00$ & 3.777 \\
BPC & RS $9.590 .494,22$ & 1.374 \\
\hline
\end{tabular}

Fonte: Portal da Transparência de Rondon do Pará, 2020. Elaborado pelos autores (2020). 
Em Rondon do Pará cerca de 15.810 habitantes já foram beneficiados pelo Auxílio Emergencial. Um dos critérios para receber o auxílio é não possuir emprego formal ativo, ou seja, não ter carteira assinada. Cerca de $29,94 \%$ da população levando em consideração a estimativa de habitantes do IBGE, estão em situação de trabalho informal, ou até mesmo desempregados, 0 que reforça a desigualdade latente e condições desiguais no território estudado. Por fim, é importante destacar que o desembolso do governo com auxílio emergencial já superou todo 0 montante do bolsa família, em seus dezessete anos de história. Os valores aproximados gastos com 0 auxílio emergencial conforme o Ministério da Economia está na faixa de 500 bilhões de reais, sendo que os recursos alocados ao bolsa família desde 2004 está na casa dos 450 bilhões de reais.

\section{O PAPEL DAS POLÍTICAS PÚBLICAS PARA A SUSTENTAÇÃO DA RENDA}

Para Suplicy (2003), a melhoria da qualidade de vida e educação em países de índices elevados de natalidade, resultam dos padrões econômicos e culturais por influenciarem as taxas demográficas, e diversas proposições sociais. Dessas questões políticas sociais, a fome pode ser considerada a mais perigosa, e consequentemente, a miséria o gatilho de inúmeras revoltas.

Siqueira (2001), assevera que o nível de pobreza e desigualdades sociais existente no país, exigem programas que consigam amenizar essa realidade, e recomenda-se que seja analisado e avaliado aferindo seus resultados. Nesse sentido, potencializaria a racionalidade política governamental, evitando que os mais desfavorecidos financeiramente sejam tributados para amortizar seus próprios benefícios, ou pior, pagar benefícios que não chegam até eles.

Para Raichelis (2000), são diversas as dificuldades enfrentadas pela sociedade mundial, e com ausência assistencial e econômica, revelam-se mais fortes nos países subdesenvolvidos em que manifestam uma acentuada desigualdade. Observa-se ainda que com o intuito de diminuir tais problemas, instituições, entidades e diversos atores sociais, precisam elaborar ações que consigam sanar estas situações adversas, sendo o principal deles, a pobreza, perante a redistribuição da riqueza social e a ideia de equidade.

Entre os possíveis benefícios que teriam o poder de amenizar essa situação desigual na sociedade, destaca-se a programa Bolsa Família, criado pela Secretaria Nacional de Renda e Cidadania (SENARC), em outubro de 2003, com o objetivo de inclusão social a milhões de famílias que enfrentam a miséria atenuando essa triste realidade de pobreza e fome (CAMPELLO, 2013; BRASIL, 2020). De acordo com o Ministério da cidadania (2020), no Estado do Pará, cerca de 
$32,64 \%$ da população é beneficiada pelo programa bolsa família, recebendo um valor médio de: $\mathrm{R} \$ 203,29$ por família.

A nível municipal, exclusivamente em agosto de 2020, 3.359 famílias foram beneficiadas por esse programa, equivalente a $24 \%$ da população de Rondon do Pará, que sem esse subsidio estariam em condições precárias financeiramente. Ainda assim, o município de Rondon do Pará considera-se abaixo da meta de atendimento do programa, pois é necessário que a gestão municipal esteja focada em prospectar, efetivar e também atualizar cadastros das famílias que se enquadram nos requisitos para começarem a receber e continuarem ou não sendo um beneficiado do programa. Em março de 2020, o valor médio de $\mathrm{R} \$ 212,53$ por família, foi repassado no município de Rondon do Pará (BRASIL, 2020).

Mas o que se tem discutido bastante é a eficiência do programa, se verdadeiramente ele tem alcançado seus objetivos iniciais. Ortiz e Camargo (2016), desenvolveram estudos que evidenciavam o impacto social do programa, no qual demonstraram que as famílias auxiliadas apresentaram aumento na sua renda, o que as amparou a alcançar um nível econômico além de mera subsistência. $O$ cumprimento das condicionalidades possibilitou que crianças e adolescentes beneficiárias frequentassem mais a escola e os postos de saúde, escapando da rua e do trabalho escravo infantil ou situações humilhantes (ORTIZ e CAMARGO, 2016).

No entanto, são muitos os críticos que asseguram que o programa prolonga a dependência dos grupos beneficiários às políticas sociais do governo. Com isso, adiante está à crítica do Nobel da Paz em 2006, o economista Muhammad Yunus, que desaprova o modelo assistencialista seguido pelo governo brasileiro ao falar sobre programas como o Bolsa Família. Para ele esse assistencialismo é importante no curto prazo, mas precisa conceder espaço para soluções a longo prazo, estimulando que os indivíduos sejam responsáveis e cooperem para a sua inclusão à sociedade.

É importante ajudar as pessoas que precisam, mas também é preciso tomar cuidado para que elas não se tornem dependentes dessa ajuda por um tempo longo demais. Um exemplo é a Europa que criou um problema nesse sentido, com várias gerações de pessoas desempregadas. É necessário pensar em ideias para tirar as pessoas dessa situação de dependência, a começar por um grupo pequeno. Esse é o desafio do negócio social proposto por Muhammad Yunus, que tem por objetivo criar fundos de investimentos para acelerar a economia solidária, de forma oposta aos negócios tradicionais que só visam a maximização do lucro (AZEVEDO, 2013; STUMPF; BERGER, 2019).

Em virtude dos fatos acometidos devido a Covid-19, um benefício de caráter emergencial foi elaborado, mediante a junção de dois outros projetos: a Renda Básica de Cidadania (Lei $n^{\circ}$ 
10.835, de 2004), este, porém, não regulamentado; e o Programa Seguro - Desemprego (Lei $n^{0}$ 7.998, de 1990), com foco no trabalhador formal desempregado mediante algumas exigências (BRASIL, 2010; 2015; CARDOSO, 2020). Dessa maneira, Cardoso (2020), aufere ainda que esse auxílio emergencial pretende amparar os trabalhadores informais, devido a omissão existente sobre a seguridade a esse tipo de trabalhador. Trovão (2020), no entanto, evidência que esse auxílio emergencial ainda não é suficiente para compensar a árdua perda desses trabalhadores nesse período de crise.

Mediante a tais necessidades desses cidadãos, Yunus (2008) defende que a solução não se resume em apenas conceder o recurso aos indivíduos, afinal, os recursos do Estado são obtidos pelo suor dos trabalhadores e empresários. Há um limite do Estado, e expansões monetárias podem gerar os mais diversos problemas no longo prazo, como desvalorização da moeda e inflação, piorando a qualidade de vida da população. 0 assistencialismo deve ser observado com críticas, afinal, se agir como um fundo de caridade, chegará o recurso aos mais vulneráveis, todavia, criará dependência e não haverá retorno para a sociedade.

Destarte, no negócio social o recurso recebido pelas famílias mais vulneráveis exercerá a função de solucionar problemas sociais, melhorando em consequência todo o entorno. A essência do negócio social consiste em projetos sustentáveis, que vão muito além de simples caridade, valorizando os indivíduos, libertando-os da situação de dependência. Logo, programas como auxilio emergencial e bolsa família são de certo muito importantes no curto prazo, todavia, são ineficazes no longo prazo. Por não criar valor dentro de uma cadeia relacionada a economia solidária, por mais que amplie o consumo, os beneficiários serão os grandes empresários, piorando as condições dos micro e pequenos.

Nesse sentido, a melhor opção ao se pensar no desenvolvimento em devir consiste em atrelar esses recursos a atividades que possam ser rentáveis, ou seja, criar dinheiro com 0 dinheiro. Se os beneficiários desses programas tivessem apoio ao empreendedorismo poderiam criar empregos para outras pessoas em situação de vulnerabilidade, melhorando toda uma rede calcada no negócio social. Programas como o bolsa família são reconhecidamente importantes, mas se fossem de fato eficazes, teríamos pessoas saindo deles, e o que se vê é exatamente 0 contrário, a cada dia mais pessoas se tornam dependentes desse tipo de assistência.

\section{CONSIDERAÇÕES FINAIS}

Diniz (2007) expõe que as discussões sobre programas sociais, como a renda mínima, repercutem há um certo período no Brasil. Isso justifica-se devido a premissa de que uma política dessa natureza necessitaria de práticas de disseminação e intermediação de políticos profissionais 
que a utilizam como campanha eleitoral. A utilização desses programas com 0 viés populista, visando a eleição e reeleição, afeta negativamente a democracia, por criar dependência ao invés de liberdade. Apesar da importância dessas medidas para se garantir uma distribuição de renda de forma mais justa, é também necessário a justiça distributiva com relação as oportunidades.

Conforme exposto ao longo do texto sobre o rendimento domiciliar per capita da região norte, o estado do Pará, possui o menor rendimento comparado com os demais Estados desta região. Já a nível municipal por meio dos dados obtidos percebe-se que o número de beneficiários do programa Bolsa Família aumentou ao longo dos anos, o que sugere uma possível dependência por parte das famílias participantes. As mesmas entram no programa e com o passar dos anos permanecem, causando uma situação de dependência.

Outro ponto importante a se levantar são os critérios para participação do programa que estipulam renda mínima para os participantes, não que isso seja errado, pois é de grande importância que se tenha diretrizes e limitações para determinar o nicho de família a ser alcançado. Porém essa situação pode ocasionar que as famílias se limitem para não sair dos critérios necessários, mantendo-os em situação de vulnerabilidade.

Em outras palavras, a depender da forma como a política pública seja percebida pelas famílias, por ter um limitador de renda para receber o recurso, pode ocasionar o desestimulo em buscar melhores condições. Dessa maneira o programa não oferece medidas que instiguem os beneficiários a progredir e sim a se estagnarem.

Dito isso, significa que o acesso há uma renda mínima equivalente a realidade enfrentada tanto regional quanto estadual, auxiliaria à distribuição de renda, mas não apenas esse fornecimento de recursos, é necessário também um amparo social e educativo para uma melhor utilização dessa renda. Pode-se dar como exemplo, a educação financeira, que seria viável para instigar qualquer sentimento empreendedor dos beneficiários, pois dessa maneira não seriam dependentes por muito tempo dessa renda, mas se tornariam diligentes de um benefício e passariam a serem propulsores de um desenvolvimento econômico municipal, e consequentemente regional.

Para que esse processo ocorra de fato, é necessário a educação econômica, consistindo em um árduo e longo processo de conscientização de todos os agentes envolvidos. Logo, para que consigam desenvolver o negócio social, é necessário que os benefícios governamentais sejam atrelados a práticas financeiramente sustentáveis, promovendo um verdadeiro programa de inclusão, calcado no desenvolvimento em devir. $\mathrm{O}$ atual modelo se comporta em sentido oposto, reforçando as desigualdades, criando dependência, e perpetuando as vulnerabilidades de uma sociedade que historicamente luta pela subsistência e sobrevivência. 


\section{REFERÊNCIAS BIBLIOGRÁFICAS}

ANTONIO SAVARIS, José. A Proteção Acidentária No Contexto Da Evolução Dos Direitos De Proteção Social. 100 anos, p. 53. Os 100 Anos da Proteção ao Acidente de Trabalho no Brasil/ Coordenação Adriane Bramante de Castro Ladenthin, Marco Aurélio Serau Junior, Melissa Folman. - Curitiba: Instituto Brasileiro de Direito Previdenciário - IBDP, 2019

ALTVATER, Elmar. Consequências Regionais da crise de endividamento global no exemplo do Pará. In: CASTRO, Edna M.R.; HĖBETTE, Jean (Org.). Na trilha dos grandes projetos: modernização e conflito na Amazônia. Belém: NAEA, 1989.

AZEVEDO, Reinaldo. Nobel da Paz diz que Bolsa Família é assistencialista e que o assistencialismo deve dar espaço a soluções de longo prazo. 2013. Veja. Disponível em: $<$ https://veja.abril.com.br/blog/reinaldo/nobel-da-paz-diz-que-bolsa-familia-e-assistencialista-eque-o-assistencialismo-deve-dar-espaco-a-solucoes-de-longo-prazo/> Acesso em: 13 out. 2020. BARROS, Ricardo Paes de Organizador; FOGUEL, Miguel Nathan Organizador; ULYSSEA, Gabriel Organizador. Desigualdade de renda no Brasil: uma análise da queda recente. 2006. Disponível em: <

https://www.ipea.gov.br/portal/index.php?option=com_content\&view=article\&id=5552>. Acesso em: 25 set 2020.

BASTOS, Daniel Schneider. $O$ direito à subsistência em xeque: um olhar sobre a Lei dos Pobres e o Ato de Emenda de 1834. História Econômica \& História de Empresas, v. 21, n. 1, 2018. BRASIL. Lei $n^{\circ} 13.134$, de 16 de junho de 2015. Altera as Leis $n^{\circ} 7.998$, de 11 de janeiro de 1990, que regula o Programa do Seguro Desemprego e o Abono Salarial e institui o Fundo de Amparo ao Trabalhador (FAT), n 10.779, de 25 de novembro de 2003, que dispõe sobre 0 seguro-desemprego para o pescador artesanal, e $n^{0} 8.213$, de 24 de julho de 1991, que dispõe sobre os planos de benefícios da Previdência Social; revoga dispositivos da Lei $n^{0} 7.998$, de 11 de janeiro de 1990, e as Leis $n^{0} 7.859$, de 25 de outubro de ... 2015.

BRASIL. Ministério da Cidadania. Programa Bolsa Família. Disponível em: < https://www.gov.br/cidadania/pt-br/acoes-e-programas/bolsa-familia>. Acesso em: 26 set 2020. CAMPELLO, Tereza et al. Programa Bolsa Família: uma década de inclusão e cidadania. Ipea, 2013.

CARDOSO, Bruno Baranda. A implementação do Auxílio Emergencial como medida excepcional de proteção social. Revista de Administração Pública, v. 54, n. 4, 2020.

CNEC; WORLEY PARSONS. Estudo de impacto ambiental Projeto Alumina Rondon.

Diagnóstico ambiental do meio socioeconômico, parte I, volume IV, 2012.

CONCEIÇÃO, Pedro et al. Relatório do desenvolvimento humano 2019. Além do rendimento, além das médias, além do presente: Desigualdades no desenvolvimento humano no século XXI. New York: Programa das Nações Unidas para o Desenvolvimento, 2019.

DINIZ, Simone. Criteria of fairness and minimum income programs. Revista Katálysis, v. 10, n. 1, p. 105-114, 2007.

DO BRASIL, CONSTITUIÇÃO FEDERATIVA. Senado federal. Secretaria de Edições Técnicas, v. 1, 2010.

DO CEARÁ, ECONÔMICA. Governo do Estado do Ceará. Instituto de Pesquisa e Estratégia e Econômica do Ceará. Cep, v. 60830, p. 120, 1986.

FLICK, Uwe. Qualidade na pesquisa qualitativa: coleção pesquisa qualitativa. Bookman editora, 2009.

GEREMEK, Bronislaw; DA ASSUNÇÃO SANTOS, Maria. A piedade e a forca: história da miséria e da caridade na Europa. 1986. 
GIL, A.C. Como Elaborar Projetos de Pesquisa. - 4ª ed. - São Paulo: Atlas; 2002. Bibliografia. ISBN 85-224-3169-8.

GOLDER ASSOCIATES BRASIL CONSULTORIA E PROJETOS LTDA. Estudo ambiental do projeto Salobo escala 24 MTPA: diagnóstico ambiental, volume I, II, III, IV e V. RT-039-51301310-0058-00-B, 2004.

GUIMARÃES, José Ribeiro Soares; DE MARTINO JANNUZZI, Paulo. IDH, indicadores sintéticos e suas aplicações em políticas públicas. Uma análise crítica. Revista Brasileira de Estudos Urbanos e Regionais (RBEUR), v. 7, n. 1, p. 73-90, 2005.

IBGE NOTÍCIAS. IBGE Divulga O Rendimento Domiciliar Per Capita 2019. 2019. Disponível em: https://agenciadenoticias.ibge.gov.br/agencia-sala-de-imprensa/2013-agencia-de-

noticias/releases/26956-ibge-divulga-o-rendimento-domiciliar-per-capita-2019. Acesso em: 09 out 2020.

KIDD, Alan. State, society and the poor in XIX Century England. London: Macmillan Press. 1999.

MALTHUS, Thomas. An essay on the principle of population. [S.I.]: Eletronic Scholarly

Publishing Project, 1998.

MARTINS, G.A. Estudo de caso: uma reflexão sobre a aplicabilidade em pesquisas no

Brasil. Revista de Contabilidade e Organizações, v. 2, n. 2, p. 9-18, jan./abr., 2008.

ORTIZ, Lúcio Rangel Alves; CAMARGO, Regina Aparecida Leite. BREVE HISTÓRICO E

DADOS PARA ANÁLISE DO PROGRAMA BOLSA FAMÍLIA. II SIPPEDES. 2016. Disponível em: $<$ https://www.franca.unesp.br/Home/Pos-graduacao/-

planejamentoeanalisedepoliticaspublicas/iisippedes2016/artigo-sippedes-bolsa-familia.pdf>

Acesso em: 09 out 2020.

PATRIQUIN, L. Agrarian capitalism and poor relief in England, 1500-1860. Basingstoke:

Palgrave Macmilliam, 2007.

PINTO, Daniela Gomes (Coord); COSTA, Marco Aurélio (Coord); MARQUES, Maria Luiza de Aguiar (Coord). $O$ índice de desenvolvimento humano municipal brasileiro. IPEA, Brasília, 2013.

RAICHELIS, R. Democratizar a Gestão das Políticas Sociais - Um Desafio a Ser Enfrentado pela Sociedade Civil. Versão revista e ampliada do texto "Desafios da gestão democrática das políticas sociais", originalmente publicado em Política Social. Módulo 03. Capacitação em Serviço Social e Política Social. Programa de Capacitação Continuada para Assistentes Sociais. Brasília, CFESS, ABEPSS, CEAD/NED-UNB, 2000. Disponível em:< http://www.fnepas.org.br/pdf/servico_social_saude/texto1-4.pdf>. Acesso em: 12 out 2020. RONDON DO PARÁ. Portal de Transparência de Rondon do Pará. 2020. Disponível em: http://www.portaltransparencia.gov.br/localidades/1506187-rondon-do-para. Acesso em: 09 out 2020.

SIQUEIRA, Rozanne. IVA uniforme com renda básica: uma proposta de reforma da política tributária e social no Brasil. Encontro Nacional de Economia, XXIX. Bahia: ANPEC, 2001. SUPLICY, Eduardo Matarazzo. Da Renda Mínima a Renda Básica no Brasil: a evolução recente de um instrumento de combate à pobreza e à desigualdade. Revista de Economia Mackenzie, v. 1, n. 1, 2003.

STUMPF, Joao Henrique; BERGER, Cristiano Riam. O impacto do programa Bolsa Família no combate à fome e a desigualdade social no Brasil. Projeção, Direito e Sociedade, v. 10, n. 2, p. 43-51, 2019.

TOWNSEND, Joseph. A dissertation on the Poor Laws. London: Ridgways, 1817. Disponível em <https://books.google.com.br/books/about/A_dissertation_on_the_

poor_laws.html?id=PZJPAAAAYAAJ\&redir_esc=y>. Acesso em: 08 out 2020. 
TROVÃO, Cassiano José Bezerra Marques. A Pandemia da Covid-19 e a Desigualdade de Renda no Brasil: Um Olhar Macrorregional para a Proteção Social e os Auxílios Emergenciais. 2020.

VAN PARIJS, Philippe. Renda básica: renda mínima garantida para o século XXI?. Estudos

Avançados, v. 14, n. 40, p. 179-210, 2000.

VISCARDI, Cláudia Maria Ribeiro. Pobreza e assistência no Rio de Janeiro na Primeira

República. História, Ciências, Saúde-Manguinhos, v. 18, p. 179-197, 2011.

WOOD, Ellen Melksins. A origem do capitalismo. Trad. Vera Ribeiro. Rio de Janeiro: Jorge Zahar, 2001.

YUNUS, Muhammad. Um mundo sem pobreza: a empresa social e o futuro do capitalismo. $1^{\text {a} e d . ~ S a ̃ o ~ P a u l o: ~ A ́ t i c a, ~} 2008$.

\section{Recebido em 20 de Fevereiro de 2021.}

Aceito para publicação em 20 de Maio de 2021.

\section{Resumo}

A Renda Básica é um tema muito discutido quando se fala em desigualdade e distribuição de renda, considerado um direito fundamental e humano, auxilia como um mecanismo na diminuição de disparidade social. Partindo deste pressuposto, este trabalho tem como objetivo verificar como se dá essa distribuição de renda no Município de Rondon do Pará com foco principalmente nas famílias que se utilizam de programas sociais para terem ou complementarem sua renda per capita. O procedimento adotado para a realização deste estudo foi uma pesquisa bibliográfica, a partir do levantamento de conceitos e referências teóricas de estudos já publicados acerca do tema, por meio eletrônico, artigos científicos, como também sites estatísticos de dados secundários do governo. Este estudo permitiu concluir que em comparação as demais regiões do Brasil, o rendimento domiciliar per capita da região Norte é considerado o menor, e quando essa analise se limita apenas aos estados da região Norte, o Estado do Pará possui o menor rendimento comparado com os demais Estados desta região. A nível municipal percebe-se que o número de beneficiários do programa Bolsa Família aumentou ao longo dos anos, o que sugere uma possível dependência por parte das famílias participantes. Conclui-se então que os programas socioeconômicos ajudam no acesso a uma renda mínima, porém é gerado uma dependência das famílias ao programa. Sugere-se que essas famílias recebam uma educação econômica, com intuito de conscientizar e promover o empreendedorismo, a inclusão social e o desenvolvimento familiar e do município.

Palavras-chave: Bolsa Família; Distribuição de renda; Políticas Públicas; Renda Básica.

\section{Abstract}

Basic Income is a much discussed topic when it comes to inequality and income distribution, considered a fundamental and human right, it helps as a mechanism to reduce social disparity. Based on this assumption, this work aims to verify how this income distribution occurs in the municipality of Rondon do Pará, focusing mainly on families that use social programs to have or supplement their per capita income. The procedure adopted for this study was a bibliographical research, based on the survey of concepts and theoretical references of studies already published on the subject, by electronic means, scientific articles, as well as statistical sites of secondary government data. This study allowed us to conclude that compared to the other regions of Brazil, the per capita household income of the North region is considered the lowest, and when this 
analysis is limited only to the states of the North region, the State of Pará has the lowest income compared to the other states of this region. At the municipal level, it is noticed that the number of beneficiaries of the Bolsa Familia program has increased over the years, suggesting a possible dependence on the part of the participating families. It is concluded that socioeconomic programs help in accessing a minimum income, but a dependence on the families to the program is generated. It is suggested that these families receive an economic education, in order to raise awareness and promote entrepreneurship, social inclusion and family and municipal development. Keywords: Bolsa Família; Income distribution; Public Policies; Basic Income.

JEL: E25, H11, 010, O20, R10, 